\title{
Estudo comparativo entre equipamentos visando à redução do vandalismo nos pontos de entrega voluntária de recicláveis
}

\section{Amanda Patrícia Oliveira Papa ${ }^{1}$, Janine Souza da Silva ${ }^{1}, *$ e Salomão José de Santana ${ }^{2}$}

${ }^{1}$ Curso de Engenharia da Produção. Centro Universitário Jorge Amado. Av. Luís Viana, 6775. Paralela. Salvador-BA, Brasil (CEP 41720-000). *E-mail: janinesouza.2@hotmail.com.

${ }^{3}$ Ministério do Exército. Escola de Administração do Exército. Rua Território do Amapá, 455. Pituba. Salvador-BA, Brasil (CEP 41830-540).

Resumo. Há muitos anos são estudadas formas de minimização no impacto ambiental, onde o lixo urbano das grandes cidades é causador de desastres ambientais por ser descartado em locais inadequados. No Município de Salvador existe o programa de coleta seletiva que conta com Pontos de Entrega Voluntária (PEV), que são equipamentos disponibilizados em pontos estratégicos espalhados pela cidade para que o cidadão deposite seus dejetos corretamente. Porém, estes equipamentos sofrem diversos tipos de ataques degradantes, desde o descarte incorreto de resíduos à destruição total. 0 presente artigo tem por objetivo comparar os tipos de equipamentos disponíveis, analisando de forma técnica a opção mais adequada para a minimização dos impactos e redução da incidência do vandalismo, que traz tantos prejuízos para o programa e para a sociedade. Os conceitos utilizados abordam temas como hábitos da sociedade e utilização dos PEV's. Através de entrevistas com os representantes dos equipamentos e responsáveis pelo programa de coleta, foram coletados dados indispensáveis para realização da análise. 0 artigo propõe uma opção de equipamento que inviabilize ao máximo as ações de degradação dos equipamentos.

Palavras-chave: Logística; Coleta seletiva; Vandalismo; Pontos de entrega voluntária (PEV).

Abstract. Comparative study between equipment for the reduction of vandalism in the voluntary delivery points of recyclable. For many years, ways of minimizing environmental impact have been studied, where urban waste from large cities causes environmental disasters because it is discarded in inappropriate places. In the Municipality of Salvador there is a selective collection program that has Voluntary Delivery Points (PEV), which are equipment made available at strategic points throughout the city so that the citizen can dispose of their waste correctly. However, these equipment suffer attacks, from
Recebido:

$14 / 05 / 2019$

Aceito:

$25 / 08 / 2019$

Disponível on line:

26/08/2019

Publicado:

31/08/2019

Acesso aberto

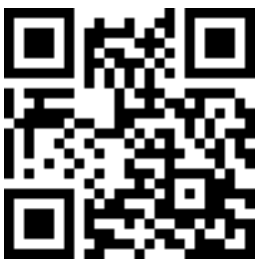

ORCID

D) 0000-0003-4468-6481 Amanda Patrícia Oliveira Papa

(C) 0000-0002-7500-0350 Janine Souza da Silva

(1) 0000-0002-1740-8921

Salomão José de

Santana 
incorrect waste disposal until the total destruction. The purpose of this article is to compare the types of equipment available, analyzing in a technical way the most appropriate option for minimizing impacts and reducing the incidence of vandalism, which causes damage to the program and to society. The concepts used cover topics such as society's habits and the use of ENPs. Through interviews with representatives of the equipment and responsible for the collection program, data were collected that were indispensable for the analysis. The article proposes an option of equipment that makes the degradation actions of the equipment as much as possible impossible.

Keywords: Logistics; Selective collect; Vandalism; Voluntary delivery points.

\section{Introdução}

0 crescimento desenfreado da população e do consumismo são fatores que fomentam os impactos ambientais no nosso planeta. $\mathrm{O}$ aumento do poder de compra, o modismo, o uso desordenado de produtos industrializados e a velocidade com que estes produtos se tornam obsoletos, incentivam a população a consumir mais do que o necessário e a descartar esses produtos com maior rapidez.

Segundo Barbosa (2010), o consumo preenche uma função acima e além daquela de satisfação de necessidades materiais. Se relaciona ao consumo de massas e para as massas, alta taxas de consumo e de descarte de mercadorias per capita, presença da moda, sociedade de mercado, sentimento permanente de insaciabilidade.

Esta necessidade de consumo aumenta a demanda na produção, trazendo a tona o problema quanto ao descarte daquilo que deixa de ser útil. 0 lixo que produzimos, em sua maioria, não tem o seu destino final alocado corretamente. Esse descarte incorreto contamina o solo, ar e água, causando inundações, aumento do número de doenças e afetando outras áreas da sociedade. Fadini e Fadini (2001) dizem que:

Do material descartado no Brasil, $76 \%$ é abandonado a céu aberto em locais impróprios, permitindo a proliferação de vetores capazes de transmitir várias doenças. A matéria orgânica disposta de forma desordenada entra em processo de putrefação, formando uma outra mistura complexa de gases de metano, dióxido de carbono, sulfídrico, amônia e outros ácidos orgânicos voláteis, os quais, quando em contato com o sistema respiratório de seres humanos, podem causar lesões irreversíveis e levar à morte.

O tratamento para resíduos sólidos no Brasil vem avançado pouco. Segundo a Associação Brasileira de Empresas de Limpeza Pública e Resíduos Especiais (ABRELPE, 2016),

O montante coletado em 2016 foi de 71,3 milhões de toneladas, o que registrou um índice de cobertura de coleta de $91 \%$ para o país, pequeno avanço comparado ao ano anterior, e que evidencia que 7 milhões de toneladas de resíduos não foram objeto de coleta e, consequentemente, tiveram destino impróprio.

\section{A Pesquisa Ciclosoft CEMPRE} (2016) traz que, 1055 municípios brasileiros (cerca de $18 \%$ do total) operam programas de coleta seletiva e apenas $10 \%$ desses munícipios estão situados na região Nordeste. Ou seja, $82 \%$ dos municípios não possuem 
nenhum programa ou incentivo à reciclagem. Ainda segundo a pesquisa, a maior parte dos municípios realiza a coleta por meio de Pontos de Entrega Voluntária (PEVs) e Cooperativas (54\%), enquanto a coleta porta-a- porta precisa de maior atenção dos gestores municipais (29\%).

De acordo com estudo realizado pelo Instituto de Pesquisa Econômica Aplicada (IPEA), cerca de 400 mil pessoas no Brasil, vivem como catadores de resíduos.Em Salvador, 08 cooperativas de reciclagem se favorecem da venda destes materiais, beneficiando aproximadamente 256 famílias. É neste contexto que o trabalho em cooperativas vem ganhando força e destaque. As cooperativas vêm ampliando sua participação no controle dos resíduos domiciliares que estão sendo reaproveitados.

A cidade de Salvador há aproximadamente três anos, não possuía nenhum programa voltado para a coleta seletiva de resíduos recicláveis. Em 2015, a prefeitura lançou o Programa de Coleta Seletiva, onde foram implantados os PEV's (Ponto de Entrega Voluntária). Essas estruturas estão disponíveis para armazenamento temporário de resíduos sólidos domésticos e destinação correta dos mesmos. Os PEV's foram inicialmente disponibilizados no modelo de contêiner (Figura 1), com capacidade de $2,5 \mathrm{~m}^{3}$ em 50 pontos da capital baiana.

Entretanto, para que haja maior eficácia dessas frentes de trabalho, é necessária uma mudança muito maior, que começa com poder público, disponibilizando condições corretas para o descarte de resíduos, e se estende aos cidadãos através da conscientização. É preciso repensar o lixo como um material que pode dar retorno benéfico à sociedade e menos agressivo ao meio ambiente.

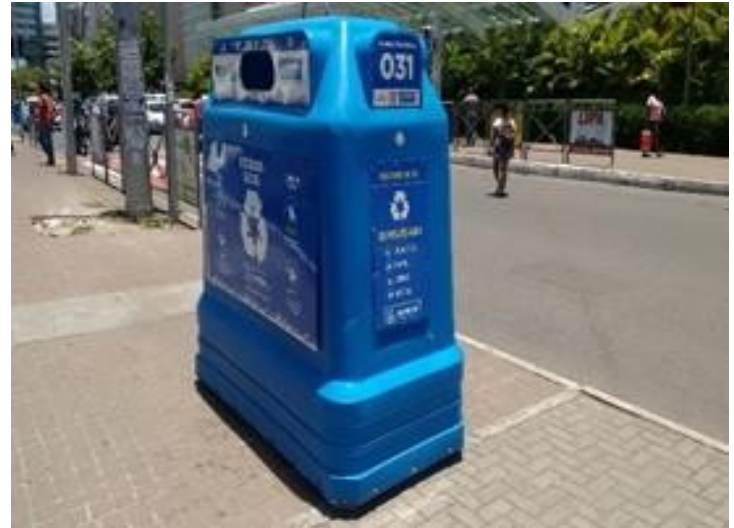

Figura 1. PEV instalado no Caminho das Árvores. Fonte: Secretaria de Cidade Sustentável (2015b).

Através do artigo "Estudo de multicasos para verificar a eficiência da logística reversa dos PEV's para o sistema produtivo das cooperativas de reciclagem de Salvador" (Bittencourt et al., 2017, no prelo), pudemos observar que além do depósito de materiais inadequados, um dos principais pontos negativos do Programa de Coleta Seletiva de Salvador é o vandalismo nos PEVs. Segundo entrevista concedida por João Resch, subsecretário da Secis (Secretaria de Cidade Sustentável), cerca de 25 PEVs foram queimados e mais 32 estão em manutenção, a maioria deles danificados por atos de vandalismo.

Este cenário dificulta muito o avanço do Programa. Com a destruição dos equipamentos, há perda de resíduos adequados para reciclagem, diminuição nos pontos disponíveis para atender aos cidadãos, além do prejuízo financeiro causado.0s recursos investidos na reposição e recuperação dos equipamentos danificados estão deixando de ser utilizados em novos equipamentos e novas iniciativas, trazendo perdas não só para a Prefeitura, de Salvador como também para a população.

0 presente estudo visa a encontrar soluções para a redução da incidência e minimização dos impactos do vandalismo, a partir da análise de 
equipamentos utilizados nos Pontos de Entrega Voluntária (PEVs), para propor à prefeitura de Salvador a melhor opção encontrada. Para isso, definiram-se como objetivos específicos: Revisar literatura sobre coleta seletiva, PEV's e vandalismo; levantar os tipos de equipamentos disponíveis no mercado e quais os tipos de vandalismo sofridos por eles; realizar uma análise comparativa entre os equipamentos $\mathrm{X}$ vandalismo.

Será usado o método comparativo e de campo para examinar de forma analítica as variáveis que interferem no sistema produtivo. 0 processo se dará por meio de entrevistas, revisão bibliográfica e levantamento de dados técnicos que se baseiam em 03 etapas distintas: A primeira será analisar o cenário atual, entrevistando gestores e buscando identificar históricos de vandalismo contra os PEVs na cidade do Salvador; A segunda etapa consistirá em identificar equipamentos disponíveis no mercadoque sirvam como alternativa para minimizar os problemas encontrados na etapa um; E por fim, a última etapa será realizar uma análise comparativa entre os equipamentos escolhidos $\mathrm{X}$ problemas encontrados, para assim concluir qual a melhor solução para o problema em questão.

\section{Resíduos sólidos urbanos}

Os resíduos sólidos urbanos (RSU's), (ABNT NBR 10.004:2004) vulgarmente denominados por lixo urbano, são resultantes da atividade doméstica e comercial. A sua composição varia de população para população, dependendo da situação socioeconômica e das condições e hábitos de vida de cada um.

Os municípios são responsáveis pela prestação dos serviços de limpeza urbana, que tem como partes integrantes, de acordo com o Instituto Brasileiro de Administração Municipal (IBAM, 2001), as etapas de geração, acondicionamento, coleta, transporte, transferência, tratamento e disposição final dos resíduos sólidos, além da limpeza de logradouros públicos.

No Brasil, o lixo orgânico representa 50\%, enquanto o lixo americano e o europeu representam entre $15 \%$ e $20 \%$, sendo todo o restante reciclável. Em algumas cidades do Brasil, apesar de existirem leis fortes e bem elaboradas sobre resíduos, a irregularidade na coleta de lixo é alta. As empresas responsáveis pela coleta prestam um serviço de má qualidade e com bastante atraso, gerando desconforto e insegurança na população e assim desencadeando uma série de problemas socioambientais.É bastante preocupante o fato de que milhões de brasileiros não têm acesso à sistemas de descarte de lixo adequado. Em 2016, foi realizada uma pesquisa pelo Compromisso Empresarial para a Reciclagem (CEMPRE), onde foi mostrado que quase 170 milhões de brasileiros não são atendidos por coleta seletiva em suas cidades, o que nos leva a crer que o país está bem longe de ter uma economia circular. Ainda segundo a pesquisa, 1.055 municípios têm programas de coleta seletiva. Como o Brasil tem mais de 5.000 cidades, esse número representa apenas $18 \%$ dos municípios. Quando se analisa a quantidade de cidadãos atendidos ou com acesso a algum programa de reciclagem, a porcentagem cai. Só 31 milhões de brasileiros - cerca de $15 \%$ da população total do país - podem contar com programas de separação do lixo, ou seja, $85 \%$ dos brasileiros não têm como destinar resíduos para a reciclagem.

Em Salvador, até o ano de 2017, eram produzidos cerca de 76.000 t/mês de resíduos sólidos, porém apenas 1\% dele era reciclado. Esse cenário que timidamente vem mudando, se dá ao reflexo dos projetos de coleta seletiva desempenhados na cidade, ações continuadas de divulgação, informações aos cidadãos e principalmente a mobilização. Estas são ações facilitadoras as quais vem alavancando o cenário de envolvimento e comprometimento social 
de diferentes grupos para a efetividade de programas de coleta seletiva.

\section{Sólidos \\ Política Nacional de Resíduos}

O Governo Federal sancionou a Lei no 12.305/2010 (Brasil, 2010), mais conhecida como a Política Nacional de Resíduos Sólidos (PNRS), que representa um marco histórico para o setor de resíduos sólidos no Brasil. Propõe a mudança de comportamento com relação ao lixo, a adoção de hábitos sustentáveis, a transparência por parte dos municípios na gestão dos resíduos, além de determinar as diretrizes para um bom gerenciamento.

A lei tem como alguns de seus objetivos a não geração, redução, reutilização, reciclagem, tratamento $\mathrm{e}$ destinação final adequada dos rejeitos. E para isso, prevê instrumentos como o plano de resíduos sólidos, a coleta seletiva, sistemas de logística reversa e outras ferramentas relacionadas à implementação da responsabilidade compartilhada pelo ciclo de vida dos produtos, a educação ambiental, entre outros.

Alvarenga (2015, p. 49), autor do artigo "Gerenciamento de Resíduos Sólidos Urbanos: uma análise de distribuição espacial dos pontos de entrega voluntária de material reciclável em Viçosa/MG", resume bem isso quando diz que um de seus mais importantes princípios é a responsabilidade compartilhada, que trouxe a obrigatoriedade para o correto manejo de resíduos sólidos entre governo, empresas e a sociedade civil. 0 poder público municipal deve realizar planos de gerenciamento do lixo e também impulsionar o retorno dos produtos após seu uso, processo no qual foi denominado de logística reversa. A lei consagra a participação formal dos catadores organizados em cooperativas na cadeia da reciclagem e estabelece, em seu Artigo 35, a obrigatoriedade da população destinar corretamente seus resíduos recicláveis caso o município já possua o serviço de coleta seletiva.

É inegável que há longo caminho à ser percorrido para que possamos observar grandes resultados, mas sem dúvidas, a PNRS reflete de maneira muito positiva para a preservação do meio ambiente, saúde da população, visual urbano, educação ambiental, mudança de hábitos, entre outros avanços necessários para desenvolvimento do nosso país.

\section{Coleta seletiva}

Coleta Seletiva é definida por Bringhenti (2004) como etapa da coleta de materiais recicláveis presentes nos resíduos sólidos urbanos, no qual deve ser separada na própria fonte geradora (cidadão, uma empresa ou outra instituição). Em seguida, deve-se acondicionar para coleta em dias e horários pré- determinados (Coleta Porta a Porta), ou realizar a entrega em Pontos de Entrega Voluntária, em Postos de Troca, a catadores, a sucateiros ou a entidades beneficentes.

A coleta seletiva traz muitos benefícios para o meio ambiente e para a sociedade. Contribui para a reciclagem, reutilização, descarte correto de materiais, redução dos aterros sanitários e lixões, diminuição da poluição (tanto do solo e lençóis freáticos, como da cidade, pois além do impacto visual, pode causar inundações, doenças e grandes prejuízos para a população e para os cofres públicos), redução de custos das empresas e também para a geração de emprego e renda. É de extrema importância o investimento por parte do poder público e engajamento da população em coleta seletiva, para melhorarmos a qualidade de vida e desenvolvimento sustentável do nosso país.

De acordo com a Política Nacional de Resíduos Sólidos, a implantação da coleta seletiva é obrigação dos municípios e metas referentes à coleta seletiva fazem parte do conteúdo mínimo que deve constar nos planos de gestão 
integrada de resíduos sólidos dos municípios.

Para o desenvolvimento de programas de coleta seletiva, é fundamental o comprometimento e envolvimento dos cidadãos. Segundo uma entrevista realizada em 2017 pela Jacqueline Bringhenthi, autora do artigo Participação social em programas de coleta seletiva de resíduos sólidos urbanos, a participação voluntária da população nos programas de coleta seletiva é muito baixa, mas pode aumentar em longo prazo.

As duas principais modalidades de coleta seletiva, que dependem diretamente da participação dos cidadãos, são a coleta Porta a Porta (PAP) e os Pontos de Entrega Voluntária (PEVs). Bringhenthi (2004) traz as vantagens e desvantagens de cada modalidade (Tabela 1).

Tabela 1. Aspectos positivos e negativos das duas principais modalidades de coleta seletiva.

\begin{tabular}{|l|l|l|}
\hline Modalidade & \multicolumn{1}{|c|}{ Aspectos positivos } & \multicolumn{1}{c|}{ Aspectos negativos } \\
\hline \multirow{5}{*}{ Porta a porta - PAP } & $\begin{array}{l}\text { - Dispensa o deslocamento até um } \\
\text { PEV; }\end{array}$ & $\begin{array}{l}\text { - Exige uma infra-estrutura maior } \\
\text { de coleta, com custos mais altos } \\
\text { para transporte; }\end{array}$ \\
\cline { 2 - 4 } & $\begin{array}{l}\text { - Permite mensurar a adesão da } \\
\text { população ao programa, } \\
\text { observando-se os materiais } \\
\text { dispostos nas calçadas. }\end{array}$ & $\begin{array}{l}\text { Encontra-se geralmente 30 dos } \\
\text { rejeitos; }\end{array}$ \\
\hline $\begin{array}{l}\text { Pontos de entrega } \\
\text { voluntária - PEVs }\end{array}$ & $\begin{array}{l}\text { - Facilita a coleta, reduzindo custos } \\
\text { compercursos longos; }\end{array}$ & $\begin{array}{l}\text { - Requer mais recipientes para } \\
\text { acondicionamento nas fontes } \\
\text { geradoras; }\end{array}$ \\
\cline { 2 - 4 } & $\begin{array}{l}\text { - Permite a exploração do espaço } \\
\text { do PEV para publicidade e eventual } \\
\text { obtenão de patrocínio; }\end{array}$ & $\begin{array}{l}\text { - Sujeito a vandalismo e eige } \\
\text { manutenção e limpeza; }\end{array}$ \\
\cline { 2 - 3 } & $\begin{array}{l}\text { Encontram-se geralmente, apenas, } \\
10 \% \text { dos rejeitos. }\end{array}$ & $\begin{array}{l}\text { - Demanda maior voluntariedade } \\
\text { da popuação, que precisa se } \\
\text { deslocar até o PEV. }\end{array}$ \\
\hline
\end{tabular}

Fonte: Bringhenti (2004).

Podemos observar na Tabela 1 que o PEV, nosso objeto de estudo, apresenta um percentual menor de rejeitos, um gasto menor com transporte e uma maior visibilidade, podendo ser usada para publicidade, patrocínio e informação. Porém, está sujeito à adesão da população, gastos com instalação e manutenção, além do vandalismo, que é considerado um dos principais problemas que interferem na eficiência dos programas de coleta seletiva.

\section{(PEV'S)}

Pontos de entrega voluntária

Segundo o Ministério do Meio Ambiente, Pontos de Entrega Voluntária (PEV's) consistem em locais situados estrategicamente próximos de um conjunto de residências ou instituições para entrega dos resíduos segregados e posterior coleta pelo poder público. Eles têm um papel extremamente importante na prática de separação do lixo para destinação final e reciclagem. 
A utilização de PEV's possibilita a participação direta da população na coleta seletiva, passando para a sociedade a ideia de compromisso conjunto, onde todos exercem seu papel para garantir a destinação correta e reaproveitamento dos resíduos sólidos recicláveis. Após a prévia separação destes materiais, o cidadão deve depositar o material em um destes pontos, que são normalmente distribuídos em locais estratégicos e de fácil acesso. Posteriormente, os materiais dispostos são recolhidos e encaminhados às cooperativas de reciclagem, onde são realizadas as etapas de triagem, armazenamento e comercialização para as indústrias responsáveis pelo processo de reciclagem.

0 principal objetivo da implantação dos PEV's é minimizar o problema gerado devido à alta demanda de descartes irregulares e auxiliar no processo de reciclagem. É um avanço para a área ambiental, um passo importante para a conscientização e incentivo no grau de cidadania, ou seja, o projeto dos PEVs possibilita e oferece uma evolução conforme a comunidade aumenta o nível de conhecimento e educação para o descarte adequado dos resíduos sólidos. Porém, o índice de vandalismo relevante contra tais equipamentos chama a atenção para o possível despreparo ou falta de informação da sociedade, e em paralelo, busca-se alternativas para que estes atos venham a ser minimizados.

Ao planejar a implantação e adequação de um equipamento de PEV, é importante levar em consideração alguns aspectos importantes para sistematizar o modo de armazenamento, transporte, coleta e principalmente observações direcionadas ao público-alvo, já que este aspecto está diretamente ligado ao perfil socioeconômico e cultural para a eficiência da estratégia adotada para conscientização e participação das pessoas no suporte ao sistema de coleta seletiva.

É importante salientar que não há regras para a escolha do sistema de coleta ou tipo de equipamento para determinada região ou situação. Cada cidade tem suas peculiaridades $\mathrm{e}$ questões condicionantes que precisam ser analisadas para a tomada de decisão do programa de coleta seletiva (Peixoto et al., 2004).

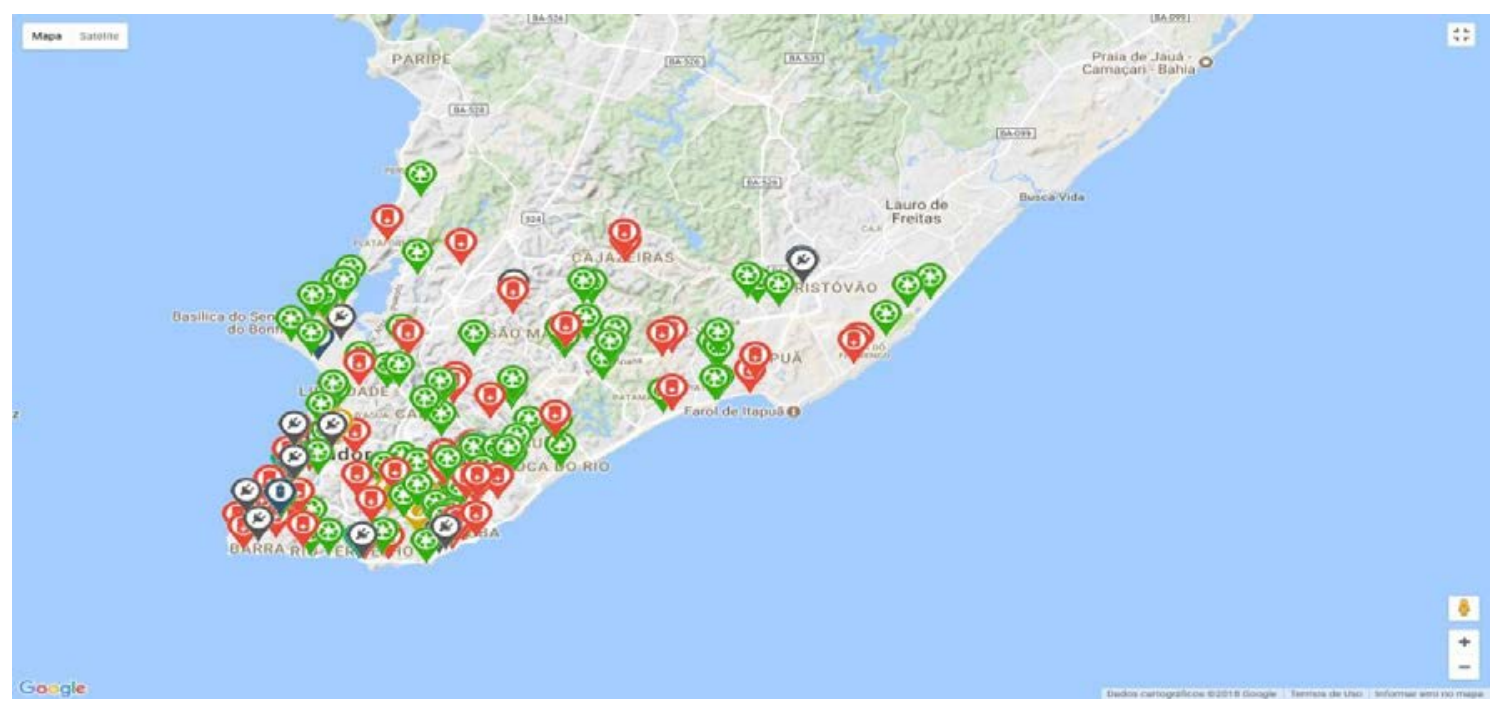

Figura 2. Mapa com localização dos PEVs em Salvador. Fonte: Prefeitura Municipal do Salvador (2018). 
Em agosto de 2015, foi implementado em Salvador o Programa de Coleta Seletiva, inicialmente com a instalação de 50 PEVs. Em dezembro do mesmo ano, esse número triplicou. Porém, em 2017, fez-se necessária a retirada de equipamentos, motivada por atitudes de vandalismo. Alguns se encontram em manutenção, enquanto outros foram totalmente perdidos.

Atualmente, a cidade dispõe de 93 PEVs distribuídos em 50 bairros. Podemos observar na Figura 2, o mapa de coletores disponíveis para entrega.

É possível ainda baixar o aplicativo disponibilizado pela prefeitura para plataformas Android (http://bit.ly/ 1gZXc34) e IOS (http://apple.co/ 1f5t58x), e acessar o site (http://www.coletaseletiva.salvador.ba. gov.br) para ter acesso ao mapa e identificar o ponto mais próximo de acordo com a sua localização, além de ter acesso a dicas, contatos e informações importantes.

\section{Tipos de equipamentos}

Existem diversos tipos de equipamentos que podem ser utilizados como PEV. Selecionamos os quatro modelos que mais se adequam ao serviço de coleta seletiva, conforme especificações abaixo.

Ecolix. 0 equipamento escolhido pela prefeitura de Salvador para ser utilizado nos Pontos de Entrega Voluntária foi o modelo Ecolix (Figura 3).

Fabricado em PEAD (Polietileno de Alta Densidade), é um equipamento atóxico e possui uma grande resistência química (praticamente imune à temperatura ambiente), 100\% virgem aditivado contra as ações dos raios UV classe 8 - UV8. Possui excelentes propriedades mecânicas, físicas, químicas e hidráulicas o que agrega ao ECOLIX uma ótima resistência ao tensofissuramento e às deformações, permitindo um tempo de vida útil 6 a 8 anos. É de fácil implantação, dispensando serviços de fundação e terraplanagem, apenas atividade de içamento através de caminhão munck (Figura 4), assim como a coleta. Tem capacidade de $2.500 \mathrm{~L}$ e suporta cargas de até $1.000 \mathrm{~kg}$. Além disso, possui amplos espaços e possibilidades para colocar adesivos com publicidade, logos e personalização em geral. 0 equipamento não exige mão de obra especializada para manutenção, ficando essa restrita à limpeza e aperto de parafusos.

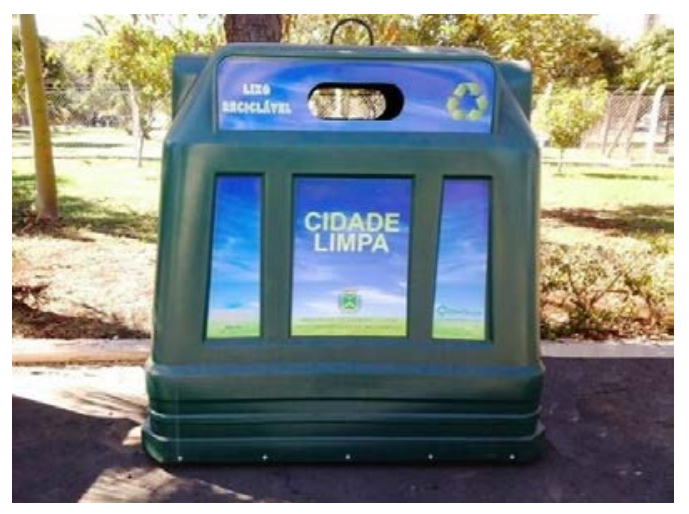

Figura 3. PEV Modelo ECOLIX. Fonte: Contemar (201-).

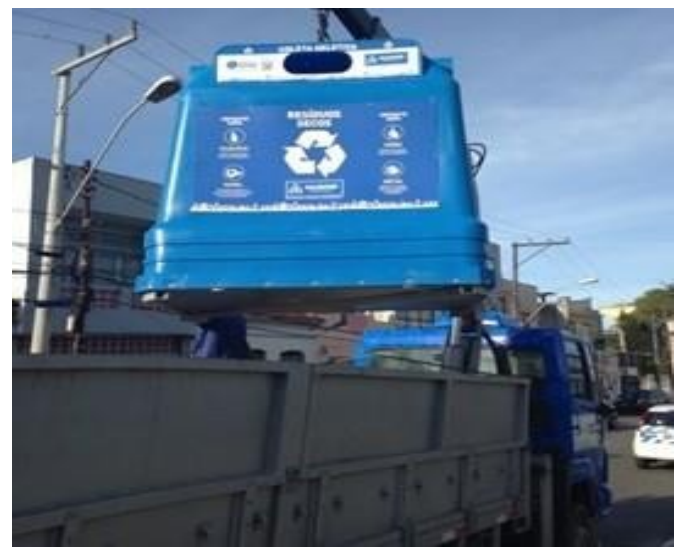

Figura 4. PEV sendo descarregado. Fonte: Secretaria de Cidade Sustentável (2015d). 


\section{Container TEU}

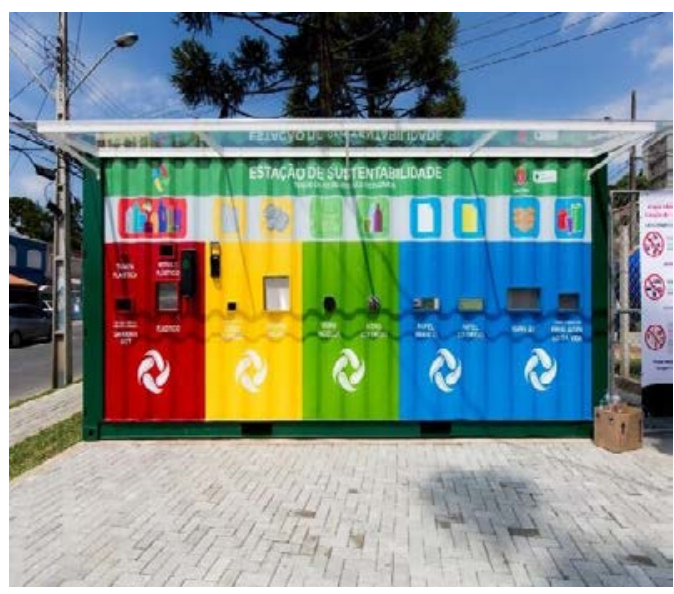

Figura 5. PEV em Container de Curitiba, Paraná. Fonte: Eco Domi ([201-]).

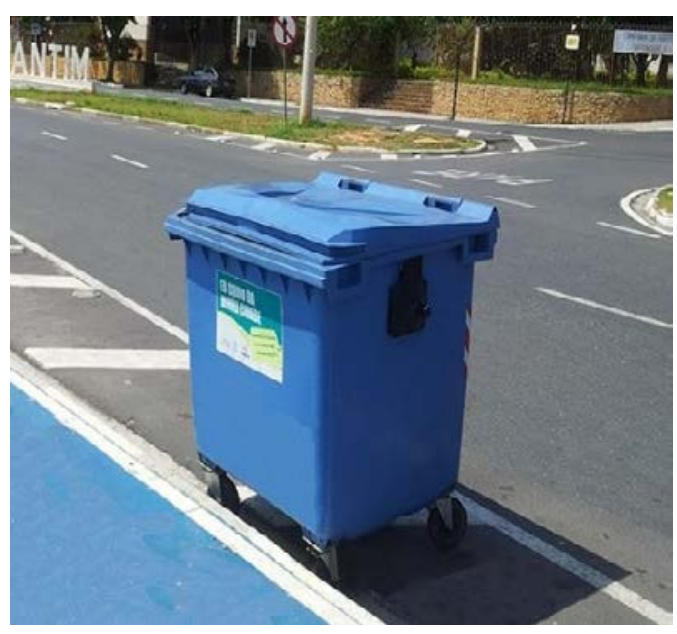

Figura 6. Contentor de 1,000 L. Fonte: Contemar ([201-a]).

A utilização do container como equipamento para coleta seletiva garante o reaproveitamento desses cofres de cargas que muitas vezes ficam abandonados em portos. Fabricados com aço corten, uma liga de aço $75 \%$ mais resistente que o aço convencional, ele é perfeito para resistir as mais variadas ações do clima. Além de poder ser mantido a céu aberto, sem comprometer a sua estrutura e sua carga. É bastante estruturado para resistir ao uso constante, além de ser resistente à chuva, incêndio e outros sinistros. No transporte de mercadorias, o container é utilizado por aproximadamente oito anos, apesar de ter uma vida útil de 100 anos, o que nos traz a necessidade de encontrar novas possibilidades de reaproveitamento. Para a utilização como PEV (Figura 5), o container passa por processo de limpeza, pintura, cortes, emolduramento das aberturas e acabamento. É de fácil implantação, não requer serviços de fundação e terraplanagem, o que o torna econômico, além de ser sustentável. Para alocação dos materiais, podemos utilizar até quatro contetores de PEAD (Figura 6), com volume de $1.000 \mathrm{~L}$ e capacidade de carga de $400 \mathrm{~kg}$ cada, com quatro rodas, facilitando a operação de descarregamento. A manutenção se restringe apenas à limpeza e retoque de pintura em caso de metal exposto, para que não haja surgimento de pontos de ferrugem. É um equipamento com material resistente, que aloca uma grande quantidade de materiais, porém, é superdimensionado e dificilmente utilizado como elemento arquitetônico.

Bauer GTE. Fabricado em aço galvanizado, acompanha recipiente de concreto onde fica instalado (Figura 7). Tem vida útil de aproximadamente 15 anos e após o período de uso, pode ser reciclado. Em sua parte subterrânea, tem capacidade para volumes de até $5 \mathrm{~m}^{3}$, podendo armazenar recicláveis, sem risco de contaminação, por conta da tecnologia de vedação. Denominado de sistema GTE, o produto é galvanizado a zinco, o recipiente não é inflamável e o esvaziamento pode ser feito com auxílio do caminhão munck. Possui 3 metros de altura, sendo que 2,10 metros ficam abaixo no nível do solo e $0,90 \mathrm{~cm}$ acima do solo, opcionalmente revestido com madeira ou chapa (Figura 8). Como ele é fabricado em módulos, caso aconteça algum acidente no momento de coleta, poderá ser trocado apenas o módulo danificado. 0 equipamento, ao contrário do ECOLIX, necessita de mão de obra especializada, os colaboradores 
responsáveis pelas manutenções internas devem ter um curso de Trabalho em espaços confinados, (NR-33), por se tratar de um ambiente não projetado para ocupação humana, que possui meios limitados de entrada e saída.

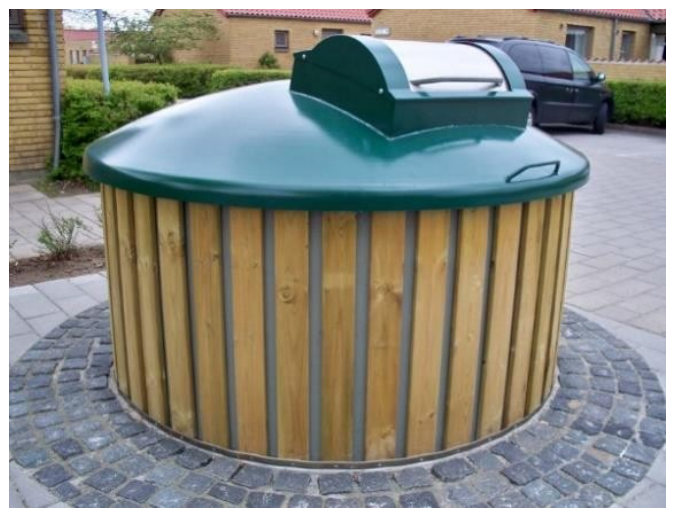

Figura 7. Container Bauer modelo GTE $5 \mathrm{~m}^{3}$. Fonte: Guajará Ambiental ([201-]).

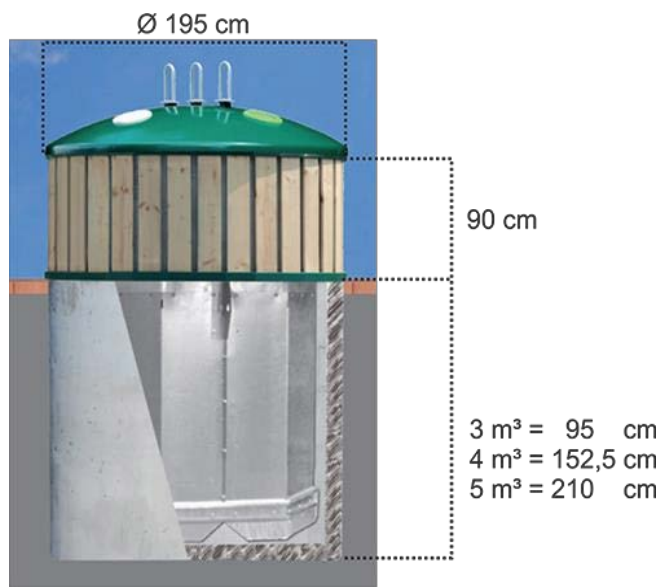

Figura 8. Dimensões do Container Bauer, modelo GTE $5 \mathrm{~m}^{3}$. Fonte: Guajará Ambiental ([201-]).

Do ponto de vista de implantação, o equipamento fica envelopado dentro de um recipiente de concreto, evitando dessa forma empuxos de terra e o contato direto com o solo, porém, para implantação mesmo é preciso movimentar um volume significativo de terra, e realizar um estudo preliminar do solo de implantação, para posterior construção no terreno escavado e estabilizado, de uma membrana impermeável de concreto armado, capaz de suportar pequenos recalques e acomodações de solo sem transferir as cargas para as chapas de zinco, que estão montadas em módulos e apresentam baixa resistência mecânica, a esses tipos de esforços.

\section{Contentor soterrado de carga}

traseira. Outra alternativa de lixeira subterrânea é o contentor soterrado de carga traseira (Figura 9). 0 equipamento possui uma estrutura metálica abaixo do solo, que é elevada por sistema hidráulico, dispondo os containers de quatro rodas para a coleta mecanizada tradicional (Figura 10), dispensando o uso de caminhão munck. A plataforma é feita em chapa e a estrutura tubular em aço galvanizado a fogo. 0 equipamento é operado por uma unidade de controle hidráulica que é acionada mediante acoplamento de engate rápido adaptado ao caminhão. 0 tempo padrão para subida e descida é de $15 \mathrm{~s}$.

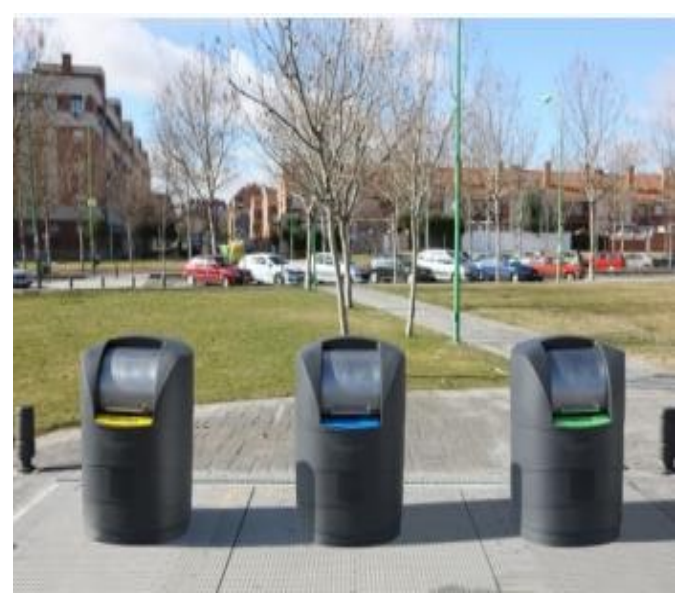

Figura 9. Contentor Soterrado Traseiro. Fonte: Contemar ([201-b]). 


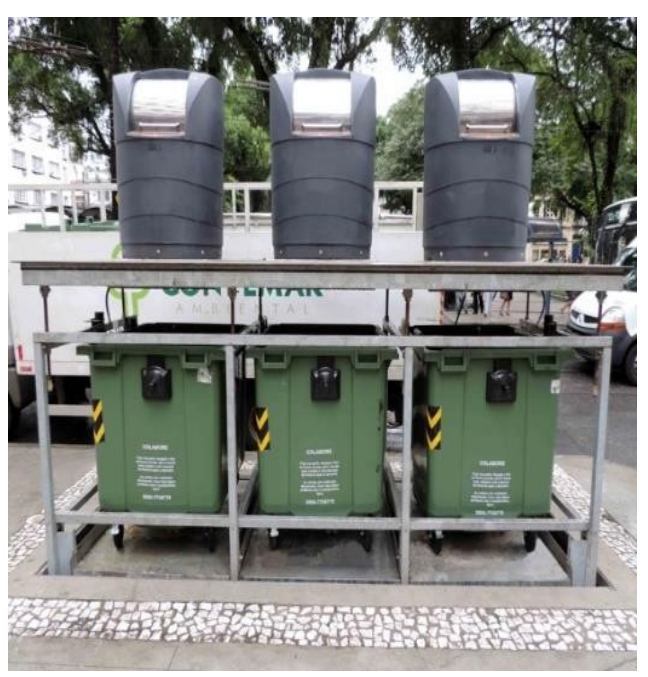

Figura 10. Contentor Elevado. Fonte: Contemar ([201-b]).

A capacidade do equipamento é de $1.000 \mathrm{~L}$ por boca, suportando cargas de até $400 \mathrm{~kg}$. Tem vida útil de 10 a 15 anos e exige manutenção a cada dois meses, variando de acordo como local onde será instalado. A instalação envolve obra civil, pois é necessário a escavação de um fosso para inserção da caixa de concreto que recepcionará o equipamento (parte estrutural do elevador). Após esse processo, são inseridas as bocas e o coletores de PEAD que estarão submersos, seguido da realização dos últimos ajustes e finalização da obra.

\section{Vandalismo}

Segundo a Secretaria Cidade Sustentável e Inovação (Secis) em novembro de 2017, 50 Pontos de Entrega Voluntária (PEVs) de resíduos descartáveis foram recolhidos pela prefeitura para manutenção, pois não estavam em condições de utilização devido aos vandalismos sofridos. Este cenário também ocorreu em julho de 2017, onde na ocasião, 11 dos 50 equipamentos recolhidos para manutenção precisaram ser substituídos pois foram incendiados. Dentre os locais que tiveram os equipamentos retirados para manutenção estão os localizados na
Praça da Lapinha (Lapinha), Largo do Guarani (Liberdade), Rua Campinas de Brotas (Brotas), Largo de Roma (Roma), Rua Monte Serrat (Monte Serrat), Rua Bambuí (São Caetano), Rua Aristides de Oliveira (Santa Mônica), Rua Doutor Eduardo Dotto (Paripe) e na Praça do Rio Sena (Rio Sena).

As ocorrências de vandalismo são divididas em três grupos:

1- Ataques graves: quando o equipamento sofre perda total e não é possível realizar sua recuperação (exemplo: queima total);

2- Ataques médios: quando o equipamento sofre ataques reversíveis (exemplo: elevação da estrutura para retirada de resíduos por catadores informais, retirada de peças, quebra da placa de informações);

3- Ataques leves: quando o equipamento sofre pequenos danos visuais (subtração de adesivo, riscos nos equipamentos).

Segundo entrevista com João Resch, subsecretário de Secretaria da Cidade Sustentável e Inovação (SECIS), até março de 2018, 25 dos 150 equipamentos instalados tinham sido queimados (ataques graves). Além da queima os equipamentos, há descarte de material inadequado (incluindo animais mortos), roubo de peças, retirada das placas informativas, pichação e depredação. Isso mostra que a destruição dos equipamentos ocorre de forma proposital e por uma parte da população que não possui educação e respeito pelos bens públicos. Prova disso é que o local com maior índice de vandalismo é o centro da cidade, onde há um grande número de moradores de ruas e usuários de drogas. Outra situação bastante recorrente é a elevação da estrutura por catadores informais, para a retirada dos resíduos recicláveis. Além da danificação dessa estrutura, os equipamentos são virados, espalhando os resíduos por todo o caminho. Por conta disso, muitos moradores entram em contato com a SECIS, solicitando a retirada dos 
equipamentos dos seus bairros, pois ao invés de cumprirem com o seu papel de reunir o lixo em um único recipiente, acaba resultando em lixo espalhado pela calçada.

Esta situação é bastante preocupante, pois interfere diretamente na eficiência do Programa de Coleta Seletiva, que além do prejuízo financeiro e insatisfação da população, não contribui de forma significativa com o trabalho realizado pelas cooperativas de reciclagem.

\section{Análise comparativa}

A partir do exposto, selecionamos alguns equipamentos utilizados como PEV, a fim de compará-los e avaliar sua viabilidade técnica, como sugestão para a redução dos impactos causados pelo vandalismo. Para isso, utilizamos os parâmetros de capacidade, espaço, implantação e manutenção, operação, custo e material associado ao vandalismo.

\section{Capacidade}

Para avaliar os equipamentos com relação à capacidade, vamos levar em consideração o volume em $\mathrm{m}^{3}$ e a capacidade de carga em kg. Para avaliação do Container TEU, vamos considerar o volume dos contetores internos.

Conforme evidenciado na Tabela 2 , não há variação na capacidade de carga por $\mathrm{m}^{3}$ dos equipamentos avaliados, todos os equipamentos suportam $400 \mathrm{~kg} / \mathrm{m}^{3}$, o que diferencia os equipamentos é a capacidade de carga total e seu volume interno. Neste caso, o de maior volume é Bauer GTE.

\section{Impacto visual}

Um aspecto importante a ser considerado é o espaço ocupado numa via pública. 0 equipamento com grandes dimensões e mal localizado, pode interferir no trânsito, prejudicando a circulação de pedestres, além do impacto visual causado, trazendo assim uma série de transtornos para a população.

Tabela 2. Análise de capacidade por volume interno.

\begin{tabular}{|c|c|c|c|c|}
\hline Volume/Capacidade & Ecolix & Container Teu & Bauer Gte & Soterrado \\
\hline Volume $\left(\mathrm{m}^{3}\right)$ & 2,5 & 4 & 5 & 3 \\
\hline Capacidade de carga (kg) & 1.000 & 1.600 & 2.000 & 1.200 \\
\hline $\mathrm{kg} / \mathrm{m}^{3}$ & 400 & 400 & 400 & 400 \\
\hline
\end{tabular}

Fonte: Elaborado pelas autoras, com dados obtidos através dos fornecedores dos equipamentos (2018).

Tabela 3. Análise das dimensões dos equipamentos.

\begin{tabular}{|l|c|c|c|c|}
\hline Dimensões & Ecolix & Container Teu & Bauer Gte & Soterrado \\
\hline Comprimento (m) & 1,765 & 6,058 & 1,950 & 2,940 \\
\hline Largura (m) & 0,747 & 2,438 & 1,950 & 1,615 \\
\hline Altura (m) & 1,778 & 2,591 & 0,900 & - \\
\hline Volume total (m $\mathbf{~ m}^{\mathbf{3}}$ & $\mathbf{2 , 3 4 4}$ & $\mathbf{3 8 , 2 6 8}$ & $\mathbf{3 , 4 2 2}$ & - \\
\hline
\end{tabular}

Fonte: Elaborado pelas autoras, com dados obtidos através dos fornecedores dos equipamentos (2018). 
A partir das dimensões apresentadas (Tabela 3), podemos perceber que o container apresenta o maior volume dentre todos os equipamentos analisados, ocupando um espaço quase $3 \mathrm{x}$ maior com relação aos outros. Além de ser um equipamento superdimensionado, apresenta capacidade de carga menor que o Bauer. Já o Ecolix, quando comparado ao Bauer, possui o dobro de altura e metade da capacidade carga, apesar de ser menor em largura. A respeito do contetor soterrado de carga traseira, possuímos apenas as dimensões da área total utilizada. A empresa não disponibizou as medidas da parte exposta do equipamento.

Com base nisso, identificamos uma das grandes vantagens dos equipamentos soterrados, pois, como os resíduos são mantidos abaixo do nível do solo, é possível armazenar uma quantidade maior, sem que haja grande ocupação do espaço da calçada e poluição visual.

\section{Implantação e manutenção}

Alguns equipamentos são de fácil implantação, enquanto outros possuem um maior grau de complexidade.

Tabela 4. Implantação e Manutenção dos equipamentos.

\begin{tabular}{|l|c|c|c|c|}
\hline & Ecolix & Container & Bauer Gte & Soterrado \\
\hline Implantação & $\begin{array}{c}\text { Através de Caminhão } \\
\text { Munck }\end{array}$ & $\begin{array}{c}\text { Através de Caminhão } \\
\text { Munck }\end{array}$ & $\begin{array}{c}\text { Necessita de obra } \\
\text { civil }\end{array}$ & $\begin{array}{c}\text { Necessita de } \\
\text { obra civil }\end{array}$ \\
\hline Manutenção & $\begin{array}{c}\text { Limpeza, aperto de } \\
\text { parafusos, troca do } \\
\text { adesivo. }\end{array}$ & $\begin{array}{c}\text { Limpeza, retoque de } \\
\text { pintura, troca de } \\
\text { adesivo. }\end{array}$ & $\begin{array}{c}\text { Limpeza com mão } \\
\text { de obra } \\
\text { especializada }\end{array}$ & $\begin{array}{c}\text { A cada 2 meses, } \\
\text { variando de } \\
\text { acordo com o } \\
\text { local onde } \\
\text { está instalado. }\end{array}$ \\
\hline
\end{tabular}

Fonte: Elaborado pelas autoras, com dados obtidos através dos fornecedores dos equipamentos (2018).

Com base nas características dos equipamentos já listados anteriormente e nas informações resumidas no quadro 4 , percebemos que os equipamentos soterrados apresentam um maior grau de complexidade no quesito implantação e manutenção, pois, necessitam de obra civil e mão de obra especializada.

Por outro lado, os equipamentos expostos, como o Ecolix e o Container TEU, são facilmente instalados através de caminhão do tipo munck e exigem manutenção de fácil execução e comum à maioria dos equipamentos, como serviços de limpeza. Outra vantagem dos equipamentos expostos é a flexibilidade. Como não são fixos, é possível mudar de local de acordo com a aceitação do público e estratégia adotada.

Neste quesito, o Ecolix se apresenta mais flexível do que o Container, por ser um equipamento com menores dimensões, mais leve e maior facilidade de adequação ao ambiente.

\section{Operação de descarregamento.}

Um fator de grande relevância é a etapa a ser realizada para a retirada dos resíduos depositados em cada equipamento.

No contentor soterrado de carga traseira, o lixo é armazenado em um recipiente abaixo do solo que possui um sensor. Quando atingido $90 \%$ da capacidade de resíduo, é 
automaticamente disparado um sinal para a central, onde a mesma providencia de imediato a retirada do lixo. Para esta operação, se faz necessário a utilização de um caminhão adaptado com mangueira hidráulica, para elevação da plataforma onde ficam armazenados os conterores, que possuem 4 rodinhas para coleta mecanizada tradicional.

O ECOLIX apresenta um sistema mais simples de operação se comparado ao soterrado. 0 equipamento possui uma espécie de tampa em sua base por onde todo o lixo é descarregado. Com auxílio de um caminhão do tipo munck, o equipamento é içado até o caminhão de coleta, onde a tampa é aberta e o todo o resíduo presente no equipamento é transferido para o caminhão coletor.

O Bauer apresenta operação semelhante ao ECOLIX, apesar de possuir parte de sua estrutura subterrânea, constitui de tampa em sua base a qual é aberta após o içamento da estrutura interna, com auxílio de um caminhão do tipo munck até o caminhão coletor onde o resíduo presente no mesmo é depositado. 0 container também possui operação de retirada de resíduo simples, porém com uso de utilitário diferente dos já mencionados nos outros equipamentos. Por possuir seu interior composto por 4 contetores com rodinhas, as mesmas são puxadas manualmente e encaixadas em uma caçamba estacionária, onde faz a transferência dos resíduos presentes nos coletores.

Podemos identificar que o ECOLIX e o Bauer possuem o mesmo procedimento para coleta. Ambos exigem caminhão de tipo munck, já utilizado na cidade de Salvador.

\section{Custo}

Um parâmetro importante para análise da viabilidade econômica de implantação dos equipamentos é o custo (Tabela 5).

Tabela 5. Custo dos equipamentos

\begin{tabular}{|l|c|l|l|c|}
\hline & Ecolix & Container Teu & Bauer Gte & Soterrado \\
\hline Custo & $5.460,00$ & $22.500,00$ & $45.000,000$ & - \\
\hline
\end{tabular}

Fonte: Elaborado pelas autoras, com dados obtidos através dos fornecedores dos equipamentos (2018).

A empresa Contemar, responsável pela fabricação e comercialização de dois dos equipamentos estudados (Ecolix e o Contentor Soterrado de Carga Traseira), informa não possuir autorização para liberação de valores. Nas pesquisas realizadas foi possível encontrar a comercialização do Ecolix pelo valor de $\mathrm{R} \$ 5.460,00$ para vendas avulsas. Já a prefeitura de Salvador, segundo entrevista com o subsecretário da SECIS, João Resch, teve um custo de aquisição de $\mathrm{R} \$ 3.500,00$ por equipamento.
O container, adaptado para coleta seletiva pela empresa Eco Domi Containers, possui um custo de $\mathrm{R} \$ 17.857,00$, não incluindo os contetores internos, que custam cerca de $\mathrm{R} \$ 1.200,00$ cada, o que totaliza um custo médio de $\mathrm{R} \$ 22.500,00$.

O BAUER apresenta um valor de R\$ 45.000,00, já incluindo instalação, podendo variar de acordo com o câmbio e frente, já que é um produto importando da Alemanha.

Com relação ao Contentor Soterrado de Carga Traseira, não foi possível localizar uma média de custo, 
principalmente por ser um serviço especializado, que envolve além do custo do equipamento, a implantação, envolvendo obra civil e instalação de elevador hidráulico.

Por conta disso, o parâmetro custo não poderá ser considerado em nossa análise por insuficiência de dados.

\section{Resistência ao vandalismo}

Como pudemos observar nas visitas aos PEV'S instalados na cidade e em entrevista com João Resch, subsecretário da SECIS, os equipamentos sofrem diversos tipos de vandalismo. 0 quadro abaixo relaciona os equipamentos estudados às ações a que são suscetíveis.

Tabela 6. Vandalismos sofridos pelos equipamentos.

\begin{tabular}{|l|c|c|c|c|}
\hline Vandalismo sofrido & Ecolix & $\begin{array}{c}\text { Container } \\
\text { Teu }\end{array}$ & Bauer Gte & Soterrado \\
\hline Queima & $\mathrm{X}$ & & & \\
\hline Pichação & $\mathrm{X}$ & $\mathrm{X}$ & $\mathrm{X}$ & $\mathrm{X}$ \\
\hline Violação do equipamento para retirada de materiais & $\mathrm{X}$ & & & \\
\hline Movimentação indevida do equipamento & $\mathrm{X}$ & & & \\
\hline Depósito de materiais inadequados & $\mathrm{X}$ & $\mathrm{X}$ & $\mathrm{X}$ & $\mathrm{X}$ \\
\hline Destruição da placa informativa & $\mathrm{X}$ & $\mathrm{X}$ & $\mathrm{X}$ & $\mathrm{X}$ \\
\hline
\end{tabular}

Fonte: Elaborado com dados obtidos através dos fornecedores dos equipamentos (2018).

\section{Queima}

Das ações de vandalismo praticadas contra os equipamentos de PEVs, a mais agressiva delas é a queima.

Dentre os equipamentos analisados, o ECOLIX é o mais sensível à essa ação.Por ser constituído de material não resistente a altas temperaturas, $\mathrm{o}$ ato de atear fogo o destrói totalmente, incapacitando sua recuperação, o que não ocorre nos outros equipamentos por serem de material resistente à temperatura elevada ou por não estarem totalmente visíveis, como no caso dos equipamentos soterrados.

\section{Pichação}

Todos os equipamentos analisados estão passíveis a sofrer pichação. Um vandalismo visual, presente em grande parte dos equipamentos instalados atualmente, é um tipo de agressão estética que está além dos parâmetros tangíveis de prevenção.

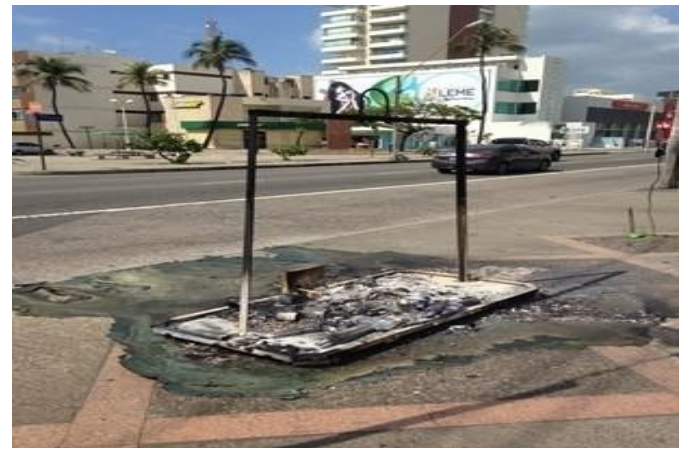

Figura 11. PEV Incendiado na Pituba. Fonte: Secretaria de Cidade Sustentável (2015a).

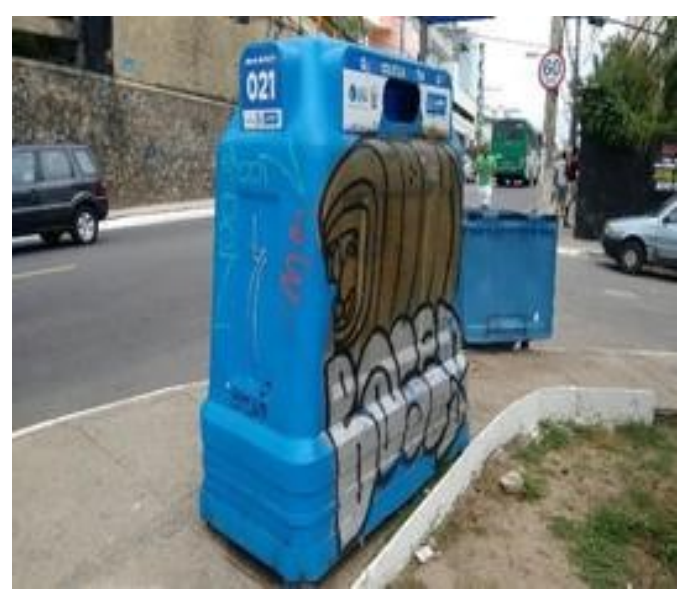

Figura 12. PEV Pichado. Fonte: Secretaria de Cidade Sustentável (2015c). 


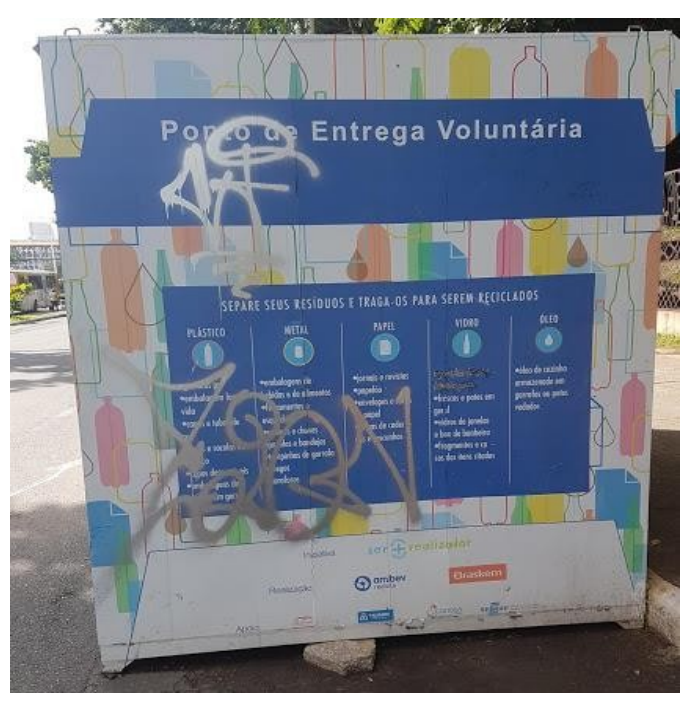

Figura 13. Container Pichado. Fonte: As autoras (2018).

\section{Violação dos equipamentos para retirada de materiais}

Alguns materiais depositados nas caixas coletoras possuem valor comercial agregado, como é o caso do alumínio. Dos equipamentos analisados, o ECOLIX é o único que está passível de rompimento por terceiros para retirada de materiais. Isso acontece por estar totalmente visível e ter material menos resistente a agressões físicas se comparado ao container, por exemplo.

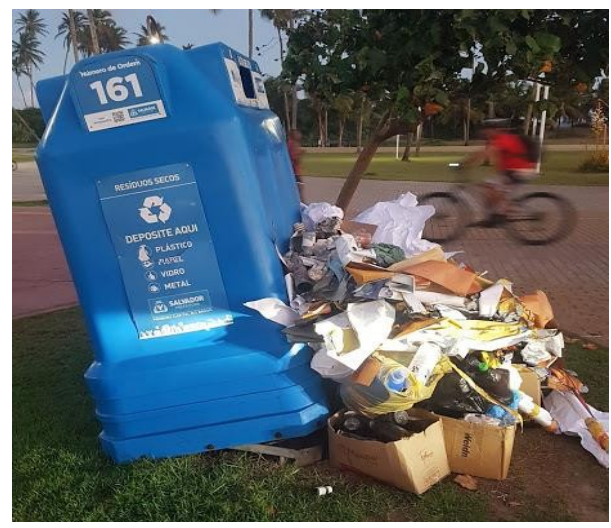

Figura 14. PEV com resíduos espalhados. Fonte: Elaborada pelos autores (2018).

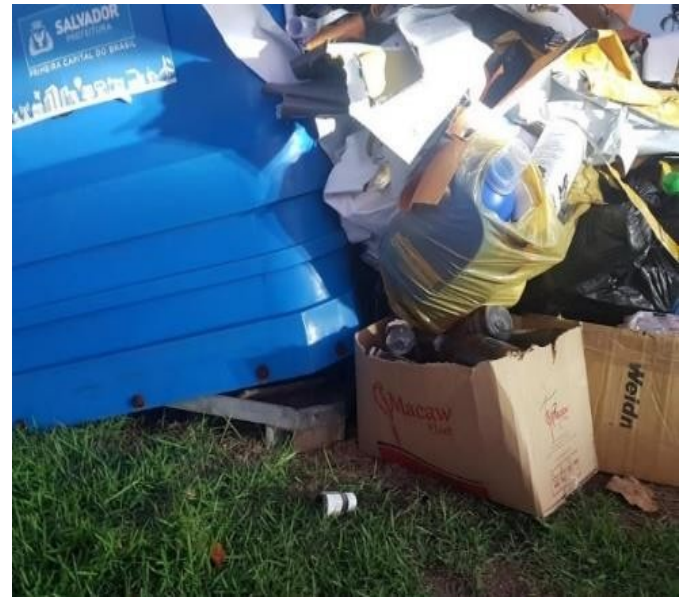

Figura 15. PEV violado em Piatã. Fonte: Elaborada pelos autores (2018).

Movimentação indevida do equipamento. Outro caso de vandalismo encontradofoi a mudança de maneira brusca do equipamento de um local para o outro. Dentre os modelos analisados, apenas o ECOLIX sofreu este tipo de dano, sendo encontrado em alguns casos, deitados nas calçadas e jogados no meio da pista. Os demais equipamentos analisados não sofrem com esse tipo de ação, por serem fixos ao chão e/ou pesados demais, como é o caso do container.

Depósito de materiais inadequados. Não é difícil encontrarmos o descarte incorreto dos materiais. Resíduos úmidos são facilmente encontrados em recipientes para resíduos secos, porque a população insiste em não separá-los previamente. Além dos resíduos úmidos ou orgânicos, são encontrados também animais mortos em recipientes de materiais recicláveis. Assim, muitos resíduos que poderiam ter uma nova destinação a partir da reciclagem,são totalmente desperdiçados devido ao depósito irregular. Todos os equipamentos estudados podem sofrer esta agressão, pois esse ponto está relacionado à informação e educação, muito além do poder de prevenção. 
Destruição da placa informativa. Todos os equipamentos disponíveis para a entrega voluntária de resíduos sólidos, possuem uma placa de identificação onde conta com a numeração do equipamento e outras informações relevantes, como qual material depositar.

Dentre os equipamentos analisados, foi comum encontrar este tipo de ato contra todos os equipamentos.

\section{Considerações finais}

A percepção sobre o cenário atual que encontramos na cidade do Salvador, é que o conhecimento sobre coleta seletiva e participação efetiva da sociedade vem avançando pouco. Os altos índices de vandalismos contra os equipamentos hoje disponíveis na cidade, denota que ainda não há uma conscientização populacional na solução do problema do lixo, grande causador de desastres ambientais.

É importante destacar que durante $o$ estudo esta visão foi identificada em todos os bairros visitados para análise dos equipamentos aqui apresentados, porém, em alguns pontos da cidade, como o centro, entendemos que estes fatores estão associados aos aspectos sociais daquela região, ao nível de instrução da população local e ausência de fatores que motivem a participação no programa.

De um modo geral, entende-se que a participação social em Salvador indica que a população entende que muitos dos materiais descartados podem ser reaproveitados, tem ciência da importância da coleta seletiva e identificamos este ponto como uma expectativa positiva.

0 estudo viabilizou que levantássemos os equipamentos utilizados como PEV e os ataques sofridos pelos mesmos, analisando e comparando-os, afim de propor uma melhor solução para mitigar a prática que traz tanto prejuízo a sociedade. Além disso, nos permitiu relizar visitas de campo para coleta de dados, o que nos ajudou a entender e conhecer o processo como um todo e o comportamento populacional de cada região da cidade diante $o$ assunto abordado neste artigo.

Ao realizar as visitas aos equipamentos, verificamos que a parte mais importante do processo de implantação dos PEVs em Salvador é a sociedade.A cidade possui vários equipamentos a disposição distribuídos em diversos bairros, como mostra a figura 2, permitindo assim que o objeto principal do programa seja efetivamente e amplamente alcançado, porém as visitas de campo mostraram que a situação atual é preocupante e isto está evidenciado nas Figuras 11 a 15.

Os principais atos de vandalismo, registrados no quadro 6 possibilitaram que estudássemos alternativas para minimização de ataques aos equipamentos, propondo uma melhor opção de forma a torná-lo acessível e mais resistente podendo economizar recursos naturais e financeiros.

Dada à importância do assunto, o presente artigo exibe uma análise comparativa de equipamentos disponíveis atualmente para entrega voluntária de resíduos sólidos pela sociedade da cidade do Salvador, desenvolvido através de recuros analíticos que permitiram a viabilidade do trabalho de forma mais rápida $\mathrm{e}$ concreta, propondo uma melhor solução dentre os equipamentos estudados.

Observamos que o ECOLIX, equipamento disponibilizado hoje pela prefeitura de Salvador, se apresenta frágil à todos os tipos de vandalismo estudados neste artigo, monstrando sua inviabilidade para esta capital.

Nesse sentido, destacamos o equipamento BAUER GTE, sistema semi-subterrâneo que apresenta características interessantes contra a probabilidade de ataques de vândalos. 0 equipamento se sobresai nos quesitos de capacidade, impacto visual e descarregamento, por ter maior volume útil, 
permitir uma boa ambientação, atuar com o mesmo sistema já utilizado na cidade, e também no quesito de resistência, ficando vulnerável apenas às ações comuns aos outros equipamentos estudados. Além disso, por ser um equipamento fechado, não permite a entrada de água da chuva, evitando a proliferação de mosquitos e danificação do material depositado.

Para mais, considera-se que é de suma importância o investimento em educação ambiental e incentivos para que a população participe mais ativamente da coleta seletiva e possa entender a sua relevância, além dos prejuízos trazidos pelos maus hábitos, não só no âmbito financeiro, mas também para o nosso planeta.

\section{Conflito de interesses}

As autoras declaram não haver conflito de interesses.

\section{Referências}

Alvarenga, J. Gerenciamento de resíduos sólidos urbanos: uma análise da distribuição espacial dos pontos de entrega voluntária de material reciclável em Viçosa/MG. Políticas Públicas \& Cidades, v. 2, n. 1, p. 45-66, 2015. Disponível em: <http://periodico.revistappc. com/index.php/RPPC/article/view/3/4>.

Acesso em: 23 abr. 2018.

ABRELPE - Associação Brasileira de Empresas de Limpeza e Resíduos Especiais. Panorama dos resíduos sólidos no Brasil 2016. São Paulo: ABRELPE, 2016. Disponível em: <http://www.abrelpe.org.br/Panorama/ panorama2016.pdf>. Acesso em: 15 mar. 2018.

ABNT - Associação Brasileira de Normas Técnicas. NBR 15.112: Resíduos da construção civil e resíduos volumosos: Áreas de transbordo e triagem: Diretrizes para projeto, implantação e operação. Rio de Janeiro: ABNT, 2004.

Barbosa, L. Sociedade de consumo. Rio de Janeiro: Zahar, 2010.

Barciotte, M. L.; Saccaro Júnior, N.L. Sensibilização e mobilização dentro da
Política Nacional de Resíduos Sólidos: desafios e oportunidades da educação ambiental. Brasília: IPEA, 2012.

Bittencourt, B.; Lima, M.; Santana, S. Estudo de multicasos para verificar a eficiência da logística reversa dos PEV's para o sistema produtivo das cooperativas de reciclagem de Salvador. Salvador: Centro Universitário Jorge Amado, 2017. (Monografia).

Brasil. Decreto no 7.404, de 23 de dezembro de 2010. Regulamenta a Lei $\mathrm{n}^{\mathrm{o}}$ 12.305, de 2 de agosto de 2010, que institui a Política Nacional de Resíduos Sólidos, cria o Comitê Interministerial da Política Nacional de Resíduos Sólidos e o Comitê Orientador para a Implantação dos Sistemas de Logística Reversa, e dá outras providências. Disponível em: <http://www.planalto.gov.br/ccivil_03/ _ato2007-2010/2010/decreto/d7404.htm>. Acesso em: 22 maio 2018.

Brasil. Lei no 12.305, de 2 de agosto de 2010. Institui a Política Nacional de Resíduos Sólidos; altera a Lei no 9.605, de 12 de fevereiro de 1998; e dá outras providências. Disponível em: <http://www.planalto. gov.br/ccivil_03/_ato2007-2010/2010/lei/ l12305.htm>. Acesso em: 22 maio 2018.

Brasil. Ministério do Meio Ambiente. Coleta Seletiva. 201-a. Disponível em: <http://www.mma.gov.br/cidadessustentaveis/residuos-solidos/catadores-demateriais-reciclaveis/reciclagem-ereaproveitamento>. Acesso em: 10 abr. 2018.

Brasil. Política Nacional de Resíduos Sólidos. 201-b. Disponível em: <http://www.mma. gov.br/cidades-sustentaveis/residuossolidos/politica-nacional-de-residuossolidos>. Acesso em: 10 abr. 2018.

Bringhenti, J. R. Coleta seletiva de resíduos sólidos urbanos: aspectos operacionais da participação da população. São Paulo: Faculdade de Saúde Pública, Universidade de São Paulo, 2004. (Tese de Doutorado). Disponível em: <http://www.teses.usp.br/ teses/disponiveis/6/6134/tde-07122009091508/pt-br.php>. Acesso em: 25 maio 2018.

CEMPRE - Compromisso Empresarial para Reciclagem. Ciclosoft 2016. Disponível em: <http://cempre.org.br/ciclosoft/id/8>.

Acesso em: 15 mar. 2018. 
Contemar Ambiental. Container de lixo C1000. 201-a. Disponível em: <http://www.contemar.com.br/produto/con tainer-de-lixo-c-1000>. Acesso em: 21 mar. 2018.

Contemar Ambiental. Contentor soterrado traseiro. 201-b. Disponível em: <http://www.contemar.com.br/produto/con tentor-soterrado-traseiro>. Acesso em: 25 mar. 2018.

Contemar Ambiental. Ecolix. 201-c. Disponível em: <http://www.contemar.com. $\mathrm{br} /$ produto/coleta-seletiva-ecolix-2500>.

Acesso em: 26 mar. 2018.

Eco Domi Containers. Por que usar container? 201-. Disponível em: <https://ecodomi.com.br/site/por-que-usarcontainer/>. Acesso em: 11 maio 2018

Fadini, P. S.; Fadini, A. A. B. Lixo: desafios e compromissos. Cadernos Temáticos de Química Nova na Escola, n. 1, p. 9-18, 2001.

Guajará Ambiental. Resíduos bem armazenados. 201-. Disponível em: <https://guajara-ambiental.com.br/>. Acesso em: 25 abr. 2018.

IBAM - Instituto Brasileiro de Administração Municipal. Manual de gerenciamento integrado de resíduos sólidos. Rio de Janeiro: IBAM, 2001.

IPEA - Instituto de Pesquisa Econômica Aplicada. Relatório de pesquisa: Pesquisa sobre pagamento por serviços ambientais urbanos para gestão de resíduos sólidos. Brasília: IPEA, 2010. Disponível em: <http://www.ipea.gov.br/portal/index.php? option=com_alphacontent $\&$ view=alphaconte nt\&Itemid=365>. Acesso em: 23 abr. 2018.

Klein, F. B.; Gonçalves-Dias, S. L. F.; Jaya, M. Gestão de resíduos sólidos urbanos nos municípios da Bacia Hidrográfica do Alto Tietê: uma análise sobre o uso de TIC no acesso à informação governamental. urbe. Revista Brasileira de Gestão Urbana, v. 10, n. 1 , p. $140-153,2018$. https://doi.org/ 10.1590/2175-3369.010.001.ao10

Peixoto, K.; Campos, V. G. B.; D’Agosto, M. A. Localização de equipamentos para coleta seletiva de lixo reciclável em área urbana. Anais do II Congresso Luso-Brasileiro para o Planejamento Urbano Regional Integrado e Sustentável, Recife, 2006.

Prefeitura Municipal do Salvador. Programa Coleta Seletiva de Salvador: pontos de entrega. 2018. Disponível em: <http://www.coletaseletiva.salvador.ba.gov. br/>. Acesso em: 25 maio 2018.

Secretaria da Cidade Sustentável. PEV incendiado na Pituba. 2015a. Altura: 534 pixels. Largura: 803 pixels. Formato: JPEG.

Secretaria da Cidade Sustentável. PEV Instalado no Caminho das Árvores. 2015b. Altura: 672 pixels. Largura: 820 pixels. Formato: JPEG.

Secretaria da Cidade Sustentável. PEV Pichado. 2015c. Altura: 660 pixels. Largura: 767 pixels. Formato: JPEG.

Secretaria da Cidade Sustentável. PEV sendo descarregado. 2015d. Altura: 561 pixels. Largura: 639 pixels. Formato: JPEG. 
Rev. Bras. Gest. Amb. Sustent., 2019, vol. 6, n. 13, p. 407-425. 